\title{
Lessons from everyday stroke care for clinical research and vice versa: comparison of a comprehensive and a research population of young stroke patients
}

\author{
Christian Tanislav ${ }^{1 * \dagger}$, Ulrike Grittner ${ }^{2,3+}$, Bjoern Misselwitz ${ }^{4}$, Gerhard Jan Jungehuelsing ${ }^{2}$, Christian Enzinger ${ }^{5}$, \\ Bettina von Sarnowski ${ }^{6}$, Jukka Putaala ${ }^{7}$, Manfred Kaps ${ }^{1}$, Peter Kropp ${ }^{8}$, Arndt Rolfs ${ }^{9}$, Turgut Tatlisumak ${ }^{7}$, \\ Franz Fazekas ${ }^{5}$, Edwin Kolodny ${ }^{10}$ and Bo Norrving ${ }^{11}$
}

\begin{abstract}
Background: Translating knowledge derived from medical research into the clinical setting is dependent on the representativeness of included patients. Therefore we compared baseline data of patients included in a recent large study addressing young stroke in comparison to a large representative stroke registry.

Methods: We analysed baseline data of 5023 patients (age 18-55 years) with an acute cerebrovascular event included in the sifap1 (Stroke in Young Fabry Patients) study. For comparison 17007 stroke patients (age 18-55 years) documented (2004-2010) in a statutory stroke registry of the Institute of Quality Assurance Hesse of the Federal State of Hesse $(\mathrm{GQH})$, Germany.

Results: Among 17007 juvenile (18-55 years) patients identified in the GQH registry 15997 had an ischaemic stroke or TIA (91\%) or an intracranial haemorrhage (9\%). In sifap1 5023 subjects were included. Sex distribution was comparable (men: 59\% sifap1 versus 60.5\% GQH) whereas age differed between the groups: median age was 46 years in sifap1 versus 49 years in $\mathrm{GQH}$. Slightly higher percentages for diabetes mellitus and hypertension in the $\mathrm{GQH}$ registry were noted. There were no differences in stroke severity as assessed by NIHSS (median 3) and mRS (median 2). In patients with ischaemic stroke or TIA ( $n=4467$ sifap1; $n=14522 \mathrm{GQH}$ ) higher rates of strokes due to small artery occlusion and atherosclerosis occurred in older age groups; cardioembolism and strokes of other determined cause occurred more frequently in younger patients.
\end{abstract}

Conclusions: The comparison of baseline characteristics between the sifap1 study and the GQH registry revealed differences mainly determined by age.

Keywords: Ischemic stroke, Stroke in the young, Stroke severity, Stroke registry

\section{Background}

Evidence-based medicine is crucial to facilitate appropriate decisions in patient care. It relies on clinical trials, cohort studies, case-control studies, case series, and observational studies. However, different sources of bias might distort results; one of the most important and

\footnotetext{
* Correspondence: christian.tanislav@neuro.med.uni-giessen.de

${ }^{\dagger}$ Equal contributors

'Department of Neurology, Justus Liebig University, Klinikstrasse 33, 35392

Giessen, Germany

Full list of author information is available at the end of the article
}

often discussed confounders is selection bias, which occurs when considering patients for inclusion in a study [1]. Potential reasons for selection bias are strict inclusion criteria determining selected patient-groups, which constitutes only a non-representative proportion of patients of the broad spectrum in the delivery of care [1]. In this context, translating knowledge derived from clinical trials and observational studies into the clinical setting is dependent on the representativeness of the patients included in studies in comparison to the entire population of interest. 
Recently, a number of large young stroke studies of single- or multi-centre design has been published. These studies brought valuable data on age and gender distribution, risk factors, etiologic factors, and imaging findings on young stroke patients [2-6]. However, it is crucial to address whether such data are identical with what is seen in daily clinical practice before adapting their conclusions to clinical practice. In this context it is important to consider possible differences between data derived from multinational projects in comparison with nation-wide data collections [2,3].

For this reason, we analysed baseline data of patients included in the recent largest observational young stroke study, namely the sifap 1 study and compared with the Hesse Stroke Registry's data on young stroke patients. Due to the selection process when searching for eligible patients within a general population of reference, differences in baseline characteristics between the two groups could be expected. The nature of the sifap1 study (screening for a rare disease among young strokes) might be a relevant determinant factor.

\section{Methods}

For the analysis two comprehensive prospective stroke populations including young patients (18-55 years) were analysed: (1) sifap1 study and (2) Register data of the Institute of Quality Assurance Hesse (Geschäftsstelle für Qualitätssicherung, GQH) [7,8]. For comparing baseline characteristics the following parameters were considered: sex, age, previous cerebrovascular event, vascular risk factors such as hypertension, diabetes mellitus and current smoking, as well as stroke subtypes according to the Trial of Org 10172 in Acute Stroke Treatment criteria (TOAST) and the stroke severity as assessed by National Institutes of Health Stroke Scale (NIHSS) and modified Rankin Scale (mRS) [9]. In the sifap1 study the NIHSS was determined within $48 \mathrm{~h}$ after admission; in GQH the NIHSS was assessed on admission while the mRS was determined one day after admission. $65.7 \%$ of the patients included in the sifap1 study are German in origin and $74 \%$ derive from German-speaking countries. The protocol for the analysis of the study was reviewed and approved by the ethical committee of the University of Giessen.

\section{sifap1}

The sifap1 study was a prospective multicentre European observational study that aimed to establish the prevalence of Fabry disease in 5023 young patients with a cerebrovascular event (CVE). Patients were recruited between April 2007 and January 2010 at 47 centres in 15 European countries. Inclusion criteria were CVE $<3$ months prior to enrolment, age 18 to 55 years, and cerebral MRI $\leq 1$ month of inclusion (Table 1). TIA was defined as a CVE with clinical symptoms lasting $<24$ hours.
Besides genetic issues the study protocol directed a detailed documentation of parameters such as vascular risk factors, stroke severity, laboratory values, and results of the diagnostic work up. All patients or their legal representatives provided written informed consent. The study was performed according to the Helsinki Declaration and has been approved by all local ethical committees of the participating centres $[2,7]$.

\section{GQH}

The GQH database is an obligatory federal-state-wide hospital-based registry that covers more than $95 \%$ of all ischaemic strokes, transient ischaemic attacks (TIA) and intracerebral haemorrhages in a community of more than 6 million inhabitants of the Federal State of Hesse (Germany). TIA was defined as a CVE with clinical symptoms lasting <24 hours. The GQH-data include various parameters of acute in-patient care, as well as factors proved to be relevant for the course and the prognosis of stroke. The acquisition of data for quality assurance reasons is regulated by law and implemented as a guideline, which is elaborated by the Federal Joint Committee for hospital quality assurance in accordance with Volume V of the Social Insurance Code ( $\$ 137$ SGB $\mathrm{V}$ and $\$ 135 \mathrm{a}$ SGB V). Based on this regulation, the Hesse State Hospital Law contains a provision that allows the $\mathrm{GQH}$ to record such data legally. The publication of aggregate quality assurance data has also been cleared with the Hesse Data Protection Commissioner, so no data protection problem arises here either [10,11].

\section{Statistical analysis}

Continuous variables were analysed by calculating the median and mean value and the interquartile range (25\%-percentile and 75\%-percentile). Nonparametric data were analysed employing the Mann-Whitney U-test. For comparing relative frequencies Chi-squared test was used. All statistical analyses were performed with the PASW Statistics 18, release version 18.0.2 (๑ SPSS, Inc., 2009, Chicago, IL, http://www.spss.com) and SAS software, version 9.2 of the SAS System for Windows (๔ 2008 SAS Institute Inc., Cary, NC).

\section{Results}

Among 151,158 documented cases between 2004 and 2010 in the Hesse Stroke Registry 17,007 cases were identified as juvenile (age $<56$ years) and 15,997 had a cerebrovascular event (91\% ischaemic stroke or TIA, 9\% intracerebral haemorrhage) (Figure 1). In the sifap1 study 5023 subjects were included; $23.3 \%$ had TIA, $70.7 \%$ brain infarction, and 5.6\% haemorrhagic strokes.

The sex distribution in both groups was comparable (males 59\% sifap1 versus $60.5 \% \mathrm{GQH}$ ). There was an obvious difference in the age distribution between the two 
Table 1 Synopsis with methodological characteristics of the sifap1 study

\begin{tabular}{ll}
\hline Study design & Observational prospective cross-sectional multicentre multinational (European) study \\
\hline $\begin{array}{l}\text { Study objectives } \\
\text { Primary objectives }\end{array}$ & To determine the prevalence of Fabry disease in young stroke patients \\
$\begin{array}{l}\text { Secondary objectives } \\
\text { Inclusion criteria }\end{array}$ & To describe patterns of stroke in young patients \\
Age & $18-55$ years \\
Time since event & Less than 3 months before inclusion into the study \\
Diagnosis & Acute CVE of any aetiology (ischemic stroke, TIA, intracranial haemorrhage) \\
Verification of diagnosis & Verification of brain infarction or haemorrhage byMRI scan.In case of negative MRI \\
& diagnosis confirmed by stroke-experienced neurologist (more than 2 years of \\
Diagnostic information & experience in stroke and at least 6 years of experience in general neurology) \\
Ethics & MRI documentation availableDiagnostic procedures according to EUSI/ESO \\
recommendations \\
Inclusion period & Written informed consent from patient or legalrepresentative according to local ethics \\
Number of participating countries & committeeregulations \\
Number of centres & April 2007 till January 2010 \\
Number of included patients & 15 \\
Overall inclusion rate in the 7 best recruiting centres & $52.9 \%$ \\
\hline
\end{tabular}

151158 cases of is chaemic stroke or TIA, bleedings and other aetiologies documented in the Hesse stroke registry (2004-2010)

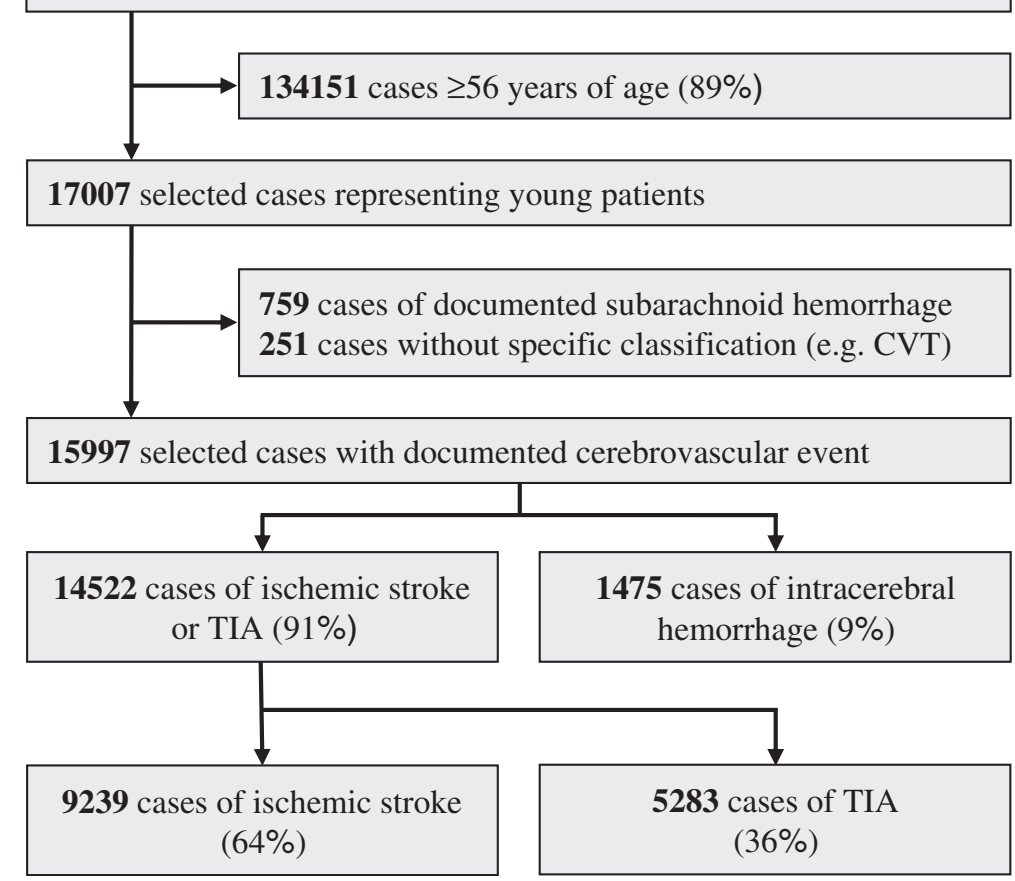

Figure 1 Patients selection within the stroke registry of the Institute of quality assurance Hesse (GQH). 


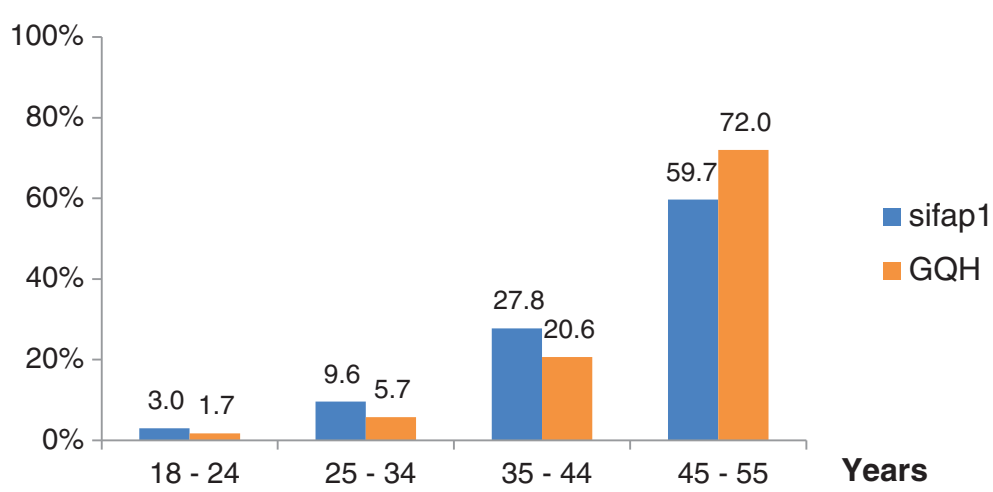

Figure 2 Age distribution stratified by age classes in sifap1 $(n=5023)$ versus GQH $(n=17007)$.

groups (Figure 2). The proportion of younger patients in sifap1 was higher, whereas in the age category 45 to 55 years a higher percentage of patients within GQH was noted compared to sifap1 (72\% versus 59.7\%; Figure 2).

Brain infarctions totalled in sifap1 a higher proportion of patients than in the GQH group (70.7\% versus $54.3 \%$, $\mathrm{p}<0.001)$. While the distribution of vascular risk factors in the two groups revealed slightly higher percentages for diabetes mellitus and hypertension in the GQH group, the stroke severity as determined by NIHSS and $\mathrm{mRS}$ were identical regarding median and interquartile ranges (Table 2).

In the subgroups of patients with ischaemic stroke or TIA the sex distribution remained similar as compared in the total groups (59.4\% males in sifap1 versus $61.2 \%$ GQH, Table 3). Considering patients with ischaemic stroke or TIA, the difference in age distribution persisted between the two groups with a three years shift (median 47 years sifap1 versus 50 years GQH). The proportion of TIA patients was higher in GQH (36.4\%) than in sifap1 (24\%); more patients with a previous stroke were included in sifap1 (16.9\% versus $11.9 \%)$. In the age category of 45-55 years the proportion of patients with hypertension was similar $(58.2 \%)$ in both groups (Table 3).

The distribution of stroke subtypes revealed a high percentage of patients classified as having an ischaemic stroke of other determined or undetermined cause in the sifap1 study (Table 3). In older age groups (comparing 45-55 years versus 18-44 years) higher rates of strokes due to small artery occlusion (GQH: $21.8 \%$ versus $12.3 \%$ and Sifap 1: $17.2 \%$ versus $8.4 \%$ ) and atherosclerosis (GQH: $26 \%$ versus $12.4 \%$ and sifap1: $21.8 \%$ versus $8.4 \%$ ) were obvious; rates of cardiac embolic strokes (GQH: $11.4 \%$ versus $13.9 \%$ and sifap1: $13.3 \%$ versus $18 \%)$ and strokes of other determined cause $(\mathrm{GQH}$ : $7.8 \%$ versus $14.9 \%$ and sifap $1: 12.8 \%$ versus $22 \%$ ) lowered from the young to the older age category in both populations (Table 3 and Figure 3).

\section{Discussion}

The main difference between the sifap1 and the corresponding GQH group represents the more left skewed age distribution in the GQH group as compared to sifap1: in sifap1 more younger patients were included, while in the GQH a higher proportion of patients aged

Table 2 Baseline characteristics, risk factors, and stroke severity

\begin{tabular}{lll}
\hline & $\begin{array}{l}\text { sifap1 } \\
(\mathbf{n}=\mathbf{5 0 2 3})\end{array}$ & $\begin{array}{l}\text { GQH } \\
(\mathbf{n}=\mathbf{1 7 0 0 7})\end{array}$ \\
\hline Sex (males) $(\mathrm{n}=5023$, sifap1) & $59 \%$ & $60.5 \%$ \\
$\begin{array}{l}\text { Age (years); median and 25th-75th } \\
\text { percentile }\end{array}$ & $46(40-51)$ & $49(44-53)$ \\
Previous (symptomatic) cerebrovascular & $16.8 \%$ & $10.9 \%^{* * *}$
\end{tabular}

event $(n=5022$, sifap1)

Event entities

\begin{tabular}{|c|c|c|}
\hline TIA & $22.3 \%$ & $31.1 \% * * * a$ \\
\hline Brain infarction & $70.7 \%$ & $54.3 \%$ \\
\hline Primary haemorrhage & $5.6 \%$ & $8.7 \%$ \\
\hline Otherst & $1.4 \%$ & $5.9 \%$ \\
\hline Missing cases & 217 & - \\
\hline \multicolumn{3}{|l|}{ ascular risk profile } \\
\hline ypertension ( $n=4994$, sifap1) & $47 \%$ & $49 \% *$ \\
\hline iabetes ( $n=4996$, sifap1) & $10 \%$ & $13.3 \% * * *$ \\
\hline urrent smoking ( $n=5022$, sifap1) & $41.4 \%$ & $38.5 \% \%^{* * *}$ \\
\hline \multicolumn{3}{|l|}{ troke severity } \\
\hline $\begin{array}{l}\text { NIH stroke scale (median; } \\
\text { 25th-75th percentile) }\end{array}$ & $3(1-6) \|$ & $3(1-6) \neq$ \\
\hline $\begin{array}{l}\text { Modified rankin scale (median; } \\
\text { 25th-75th percentile) }\end{array}$ & $2(1-3) \|$ & $2(1-3) \S$ \\
\hline
\end{tabular}

tconsider subarachnoid haemorrhage and cerebral sinus or vein thrombosis.

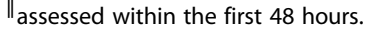

fassessed on admission.

§assessed one day after admission.

${ }^{*} \mathrm{p}<0.05$.

${ }^{* *} p<0.01$.

*** $\mathrm{p}<0.001$

a the test statistic was calculated by using all entity categories. 
Table 3 Subgroup of ischaemic strokes or TIA stratified by age groups (demographic characteristics, risk factors, and stroke subtypes)

\begin{tabular}{|c|c|c|c|c|c|c|c|c|}
\hline & \multicolumn{2}{|c|}{ Total groups } & \multicolumn{2}{|c|}{ Age $18-34$ years } & \multicolumn{2}{|c|}{ Age $35-44$ years } & \multicolumn{2}{|c|}{ Age $45-55$ years } \\
\hline & $\operatorname{sifap} 1(n=4467)$ & $\mathrm{GQH}(\mathrm{n}=14522)$ & $\begin{array}{l}\text { sifap1 }(n=563) \\
12.6 \%\end{array}$ & $\begin{array}{l}\mathrm{GQH}(\mathrm{n}=1049) \\
7.2 \%^{* * *}\end{array}$ & $\begin{array}{l}\operatorname{sifap} 1(n=1224) \\
27.4 \%\end{array}$ & $\begin{array}{l}\text { GQH(n=2962) } \\
20.4 \%^{* * *}\end{array}$ & $\begin{array}{l}\operatorname{sifap} 1(n=2680) \\
60 \%\end{array}$ & $\begin{array}{l}\mathrm{GQH}(\mathrm{n}=10511) \\
72.4 \%^{* * *}\end{array}$ \\
\hline Sex (males); $(n=4467$, Sifap1) & $59.4 \%$ & $61.2 \% *$ & $42.8 \%$ & $46.3 \%$ & $57.9 \%$ & $57.9 \%$ & $63.5 \%$ & $63.5 \%$ \\
\hline $\begin{array}{l}\text { Age (years); mean, median and 25th-75th } \\
\text { percentile ( } n=4467 \text {, Sifap1) }\end{array}$ & $44.747(40-51)$ & $47.5^{* * *} 50(44-53)$ & $28.329(25-32)$ & $28.429(25-32)$ & $40.541(38-43)$ & $40.641(39-43)$ & $50.150(47-53)$ & $51.4^{* * *} 51(48-53)$ \\
\hline $\begin{array}{l}\text { Previous cerebrovascular event } \\
(n=4466 \text {, Sifap1) }\end{array}$ & $16.9 \%$ & $11.9 \% * * *$ & $12.8 \%$ & $7.7 \% * *$ & $15.4 \%$ & $8.2 \% * * *$ & $18.6 \%$ & $13.3 \% * * *$ \\
\hline Proportion of TIA ( $n=4467$, Sifap1) & $24.0 \%$ & $36.4 \% * * *$ & $21.8 \%$ & $41.5 \% \%^{* * *}$ & $25.1 \%$ & $39.7 \% * * *$ & $23.9 \%$ & $34.9 \% * * *$ \\
\hline \multicolumn{9}{|l|}{ Vascular risk profile } \\
\hline Hypertension ( $n=4439$, Sifap1) & $46.6 \%$ & $49.5 \% \%^{* *}$ & $13.1 \%$ & $11.6 \%$ & $36.7 \%$ & $31.7 \% * *$ & $58.2 \%$ & $58.2 \%$ \\
\hline Diabetes mellitus ( $n=4443$, Sifap1) & $10.3 \%$ & $14.4 \% * * *$ & $2.0 \%$ & $3.1 \%$ & $7.7 \%$ & $8.6 \%$ & $13.3 \%$ & $17.1 \%^{* * *}$ \\
\hline Current smoking ( $n=4466$, Sifap1) & $42.5 \%$ & $40.8 \% *$ & $37.5 \%$ & $33.5 \%$ & $42.1 \%$ & $41.3 \%$ & $43.8 \%$ & $41.5 \%$ \\
\hline Stroke subtypes according to TOAST & $n=4345$ & $n=14169$ & $\mathrm{n}=555$ & $n=1006$ & $n=1201$ & $\mathrm{n}=2902$ & $n=2589$ & $n=10261$ \\
\hline Atherosclerosis & $16.4 \%$ & $22.3 \% * * * a$ & $4.1 \%$ & $8.8 \% * * * a$ & $10.4 \%$ & $13.6 \% * * * a$ & $21.8 \%$ & $26 \% * * * a$ \\
\hline Cardiac embolic source & $15.1 \%$ & $12.1 \%$ & $18.6 \%$ & $15.3 \%$ & $17.7 \%$ & $13.4 \%$ & $13.2 \%$ & $11.4 \%$ \\
\hline Small artery occlusion & $13.7 \%$ & $19.2 \%$ & $6.3 \%$ & $8.2 \%$ & $9.5 \%$ & $13.7 \%$ & $17.2 \%$ & $21.8 \%$ \\
\hline Other determined cause & $16.5 \%$ & $9.8 \%$ & $24.5 \%$ & $16.7 \%$ & $20.8 \%$ & $14.3 \%$ & $12.8 \%$ & $7.8 \%$ \\
\hline Undetermined cause & $38.3 \%$ & $36.7 \%$ & $46.5 \%$ & $51.0 \%$ & $41.6 \%$ & $45.0 \%$ & $34.9 \%$ & $33.0 \%$ \\
\hline
\end{tabular}

${ }^{*} \mathrm{p}<0.05$

${ }^{* * \mathrm{p}}<0.01$

${ }^{a}$ the test statistic was calculated by using all five TOAST classification categories. 


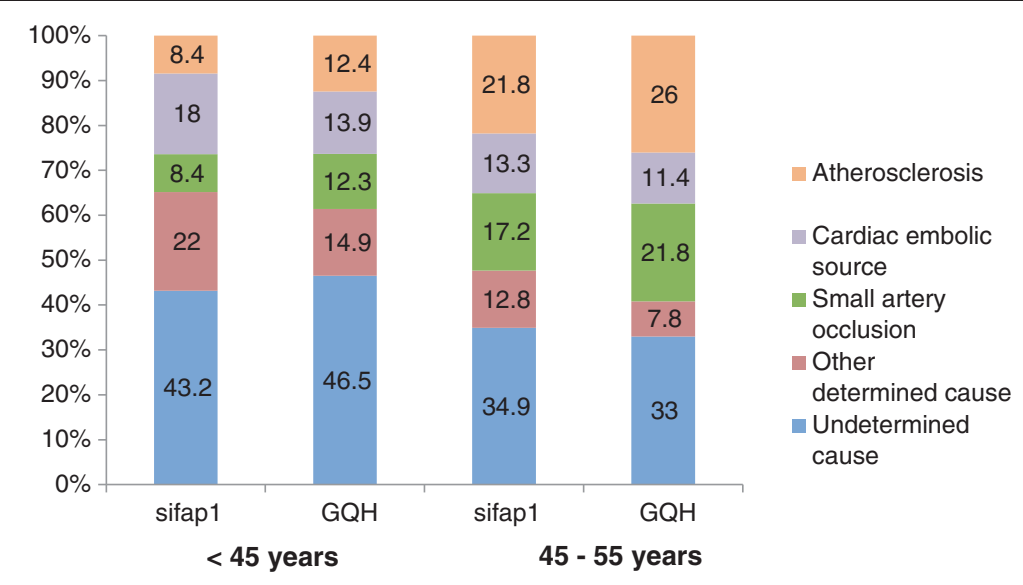

Figure 3 Stroke subtypes stratified by age sifap 1 versus GQH.

45-55 were evident. This result is in line with previous investigations, revealing comparable differences when considering the entire population of young stroke patients in sifap1 centres compared to those patients included in sifap1 [7].

However, in both groups (sifap1 and GQH) the age distribution is skewed to the left: when creating smaller age categories the proportions of patients were higher in older age groups (Figure 2). In accordance with previous investigations in both populations higher percentages of vascular risk factors in elderly patients were observed $[2,3,12,13]$. In this context the markedly higher proportion of vascular risk factors in the GQH registry might partially be determined by the higher proportion of older patients in the registry as compared to sifap1. In the sifap1 study, which specifically addressed stroke in the young, a selection bias for recruiting particularly younger patients could be suspected. In contrast in the GQH this phenomenon is of minor importance, as the registry regards to the entirety of strokes without any restrictions.

In the subgroups of patients with ischaemic stroke or TIA the difference in age might determine the distribution of aetiologies as well. In older aged patients lower proportions of cardioembolic strokes, strokes of other determined cause or undetermined cause were obvious, whereas proportions of stroke causes, such as atherosclerosis and small artery occlusion were higher in older aged patients. The higher age level in the GQH affected differences in the prevalence of stroke aetiologies between sifap1 and GQH data (Figure 3). Nevertheless the distributions of aetiologies in both collectives seem comparable with a consistent association between age and prevalence differences. This underlines the reliability of the data accumulated in the sifap1 study and GQH registry, respectively.

In the subgroup of patients with ischaemic stroke or TIA the proportion of previous cerebrovascular events in the sifap1 study was markedly higher than in the GQH data (16.9\% versus $11.9 \%$ ). The proportion of TIAs is higher in the GQH-data than in sifap1. Regarding the very young subgroups (18-44 years), in sifap1 the proportion of patients with a previous cerebrovascular event doubled the corresponding value in GQH $(14.5 \%$ versus $7.7 \%$ ).

In young stroke patients with a previous cerebrovascular event and predominantly without vascular risk factors and with unknown cause for stroke, considering Fabry disease as a potential differential diagnosis appears mandatory, and might facilitate the inclusion in sifap 1 a welcome option [14]. On the other hand previous cerebrovascular events might be missed in a global registry due to less rigorous requirements regarding imaging procedures and data acquisition. For inclusion in the sifap1 study a cerebral MRI scan was mandatory. In the GQH registry in $73 \%$ of patients with ischaemic stroke or TIA underwent the procedure during the acute treatment (unpublished data considering patients $(n=4783)$ documented 2009-2010 in the GQH registry; for these two years a consistent documentation of cerebral MRI was available). This might also determine the higher proportion of patients diagnosed with a TIA in the GQH registry.

Comparing the entire populations, the proportion of brain haemorrhages in the GQH stroke registry ranged higher $(8.7 \%$ versus $5.6 \%)$ than in sifap1. The restraint in including bleedings in sifap 1 might be also determined by the nature of the study, as cerebral haemorrhages are rarely accompanied by Fabry disease $[15,16]$.

The evaluation of the disability data rendered similar results in sifap1 and GQH; both scales (mRS, NIHSS) showed identical median and interquartile values. With regard to stroke severity, the populations are therefore comparable. Considering that in clinical trials or observational studies severely disabled patients are less selected for inclusion, due to difficulties in handling, in 
sifap1 this aspect was obviously less relevant. In conclusion, concerning the stroke severity the sifap 1 study is adequately balanced with distributions approaching the situation in the care delivery as reflected in the GQH stroke registry.

Similarly to the stroke severity, the sex distribution is comparable in both groups, with somewhat higher proportions of women in sifap1. In older age the proportion of males is higher than in younger age groups. Among the oldest age range (45-55 years) the vascular disease might preponderate in males more than in females, determining more strokes related to a vascular burden such as atherosclerotic strokes or strokes due to small artery occlusion among males $[3,17]$. When including patients in a clinical study addressing stroke or a rare disease causing stroke the patient's sex per se could not be expected to influence on the behaviour regarding inclusion. Therefore the almost identical sex distribution in both groups renders a reciprocal validation in the reliability of the accumulated data in sifap1 and GQH, respectively.

\section{Conclusion}

Differences in baseline characteristics between the sifap1 study and the GQH stroke registry were noted. They were mainly determined by age. In these specific patient groups including young strokes ( $\leq 55$ years) the median age in the sifap1 study was 3 years below the median in the GQH. Stroke aetiologies determined by vascular burden were more often present in older patients, whereas undetermined stroke causes and stroke of other determined aetiologies occurred less frequent. Especially among the young groups (18-44) high proportions of cryptogenic strokes were evident in the sifap1 study as well as in the GQH stroke registry (43\% and 46\%). Comparable sex distributions in sifap1 and GQH, in this particular case a factor robust against selection bias, underline the reliability of the data accumulated in both collectives.

Sifap1 represents a pivotal study on young stroke providing important information on distribution of risk and etiologic factors. One of the novel findings depicted in sifap1 is the high prevalence of vascular risk factors in young stroke patients [2]. In this context, the comparison with a comprehensive population is of high relevance and need to be taken into consideration when referring to sifap1. It indicates, that in a general population of young strokes, even higher percentages of vascular risk factors (hypertension and diabetes) and stroke aetiologies related to a vascular burden (arteriosclerosis and small artery occlusion) might be expected. It emphasises the need of new strategies in the primary stroke prevention considering the substantial contribution of vascular risk factors for causing strokes in young age.

\section{Competing interest}

The authors declare that they have no conflicts of interest that may be relevant to the submitted work. All authors have completed the Unified Competing Interest form at http://www.icmje.org/coi_disclosure.pdf (available on request from the corresponding author)

\section{Authors' contributions}

The present analysis was conducted by UG and CT. All authors were involved in the analysis and interpretation of the data and in drafting the manuscript. All authors read and approved the final manuscript.

\section{Sponsors' role in design and conduction of the study, data analysis} and interpretation

The sponsors of the study had no role in the study design, data collection, data analysis, interpretation, writing of the manuscript, or the decision to submit the manuscript for publication.

The corresponding author had full access to all of the data in the study and takes full responsibility for the integrity of the data and the accuracy of the data analysis, and had the final responsibility for the decision to submit for publication.

\section{Funding}

The sifap1 study (Stroke in Young Fabry Patients, www.sifap.eu; www. clinicaltrials.gov: No. NCT00414583) has been supported partially by an unrestricted scientific grant from Shire Human Genetic Therapies.

\section{Author details}

${ }^{1}$ Department of Neurology, Justus Liebig University, Klinikstrasse 33, 35392 Giessen, Germany. ${ }^{2}$ Center for Stroke Research, Charité - University Medical Centre Berlin, Berlin, Germany. ${ }^{3}$ Department for Biostatistics and Clinical Epidemiology, Charité - University Medical Centre Berlin, Berlin, Germany. ${ }^{4}$ Institute of Quality Assurance Hesse (Geschäftsstelle Qualitätssicherung Hessen; GQH), Eschborn/Frankfurt, Germany. ${ }^{5}$ Department of Neurology, Medical University of Graz, Graz, Austria. ${ }^{6}$ Department of Neurology, University Medicine, Ernst Moritz Arndt University, Greifswald, Germany. ${ }^{7}$ Department of Neurology, Helsinki University Central Hospital, Helsinki, Finland. ${ }^{8}$ Institute of Medical Psychology and Medical Sociology Medical Faculty, University of Rostock, Rostock, Germany. ${ }^{9}$ Albrecht-Kossel Institute for Neuroregeneration, University of Rostock, Rostock, Germany. ${ }^{10}$ New York University School of Medicine, New York, USA. ${ }^{11}$ Department of Neurology, Lund University Hospital, Lund, Sweden.

Received: 10 September 2013 Accepted: 11 February 2014 Published: 7 March 2014

\section{References}

1. Miller KD, Rahman ZU, Sledge GW Jr: Selection bias in clinical trials. Breast Dis 2001, 14:31-40.

2. Rolfs A, Fazekas F, Grittner U, Dichgans M, Martus P, Holzhausen M, Bottcher T, Heuschmann PU, Tatlisumak T, Tanislav C, Jungehulsing GJ, Giese AK, Putaala J, Huber R, Bodechtel U, Lichy C, Enzinger C, Schmidt R, Hennerici MG, Kaps M, Kessler C, Lackner K, Paschke E, Meyer W, Mascher H, Riess O, Kolodny E, Norrving B: Acute cerebrovascular disease in the young: the Stroke in Young Fabry Patients study. Stroke 2013, 44:340-349.

3. Putaala J, Metso AJ, Metso TM, Konkola N, Kraemer $Y$, Haapaniemi E, Kaste M, Tatlisumak T: Analysis of 1008 consecutive patients aged 15 to 49 with first-ever ischemic stroke: the Helsinki young stroke registry. Stroke 2009, 40:1195-1203.

4. Yesilot Barlas N, Putaala J, Waje-Andreassen U, Vassilopoulou S, Nardi K, Odier C, Hofgart G, Engelter S, Burow A, Mihalka L, Kloss M, Ferrari J, Lemmens R, Coban O, Haapaniemi E, Maaijwee N, Rutten-Jacobs L, Bersano A, Cereda C, Baron P, Borellini L, Valcarenghi C, Thomassen L, Grau AJ, Palm F, Urbanek C, Tuncay R, Durukan TA, van Dijk EJ, de Leeuw FE, et al: Etiology of first-ever ischaemic stroke in European young adults: the 15 cities young stroke study. Eur J Neurol 2013, 20:1431-1439.

5. Bhalla A, Grieve R, Rudd AG, Wolfe CD: Stroke in the young: access to care and outcome; a Western versus eastern European perspective. J Stroke Cerebrovasc Dis 2008, 17:360-365.

6. Varona JF, Bermejo F, Guerra JM, Molina JA: Long-term prognosis of ischemic stroke in young adults. Study of 272 cases. J Neurol 2004, 251:1507-1514. 
7. Rolfs A, Martus P, Heuschmann PU, Grittner U, Holzhausen M, Tatlisumak T, Bottcher T, Fazekas F, Enzinger C, Ropele S, Schmidt R, Riess O, Norrving B: Protocol and methodology of the Stroke in Young Fabry Patients (sifap1) study: a prospective multicenter European study of 5,024 young stroke patients aged 18-55 years. Cerebrovasc Dis 2011, 31:253-262.

8. Foerch C, Misselwitz B, Sitzer M, Berger K, Steinmetz H, Neumann-Haefelin T: Difference in recognition of right and left hemispheric stroke. Lancet 2005, 366:392-393.

9. Adams HP Jr, Bendixen BH, Kappelle LJ, Biller J, Love BB, Gordon DL, Marsh EE III: Classification of subtype of acute ischemic stroke. Definitions for use in a multicenter clinical trial. TOAST. Trial of Org 10172 in Acute Stroke Treatment. Stroke 1993, 24:35-41.

10. Stolz E, Hamann GF, Kaps M, Misselwitz B: Regional differences in acute stroke admission and thrombolysis rates in the German federal state of Hesse. Dtsch Arztebl Int 2011, 108:607-611.

11. Jauss M, Schutz HJ, Tanislav C, Misselwitz B, Rosenow F: Effect of daytime, weekday and year of admission on outcome in acute ischaemic stroke patients treated with thrombolytic therapy. Eur I Neurol 2010, 17:555-561.

12. Varona JF, Guerra JM, Bermejo F, Molina JA, de la Gomez CA: Causes of ischemic stroke in young adults, and evolution of the etiological diagnosis over the long term. Eur Neurol 2007, 57(4):212-218.

13. von Sarnowski B, Putaala J, Grittner U, Gaertner B, Schminke U, Curtze S, Huber R, Tanislav C, Lichy C, Demarin V, Basic-Kes V, Ringelstein EB, Neumann-Haefelin T, Enzinger C, Fazekas F, Rothwell PM, Dichgans M, Jungehulsing GJ, Heuschmann PU, Kaps M, Norrving B, Rolfs A, Kessler C, Tatlisumak T: Lifestyle risk factors for ischemic stroke and transient ischemic attack in young adults in the Stroke in Young Fabry Patients study. Stroke 2013, 44:119-125.

14. Rolfs A, Bottcher T, Zschiesche M, Morris P, Winchester B, Bauer P, Walter U, Mix E, Lohr M, Harzer K, Strauss U, Pahnke J, Grossmann A, Benecke R: Prevalence of Fabry disease in patients with cryptogenic stroke: a prospective study. Lancet 2005, 366:1794-1796.

15. Nakamura K, Sekijima Y, Nakamura K, Hattori K, Nagamatsu K, Shimizu Y, Yasude T, Ushiyama M, Endo F, Fukushima Y, Ikeda S: Cerebral hemorrhage in Fabry's disease. J Hum Genet 2010, 55:259-261.

16. Sims K, Politei J, Banikazemi M, Lee P: Stroke in Fabry disease frequently occurs before diagnosis and in the absence of other clinical events: natural history data from the Fabry Registry. Stroke 2009, 40:788-794.

17. Spengos K, Vemmos K: Risk factors, etiology, and outcome of first-ever ischemic stroke in young adults aged 15 to 45 - the Athens young stroke registry. Eur J Neurol 2010, 17:1358-1364.

doi:10.1186/1471-2377-14-45

Cite this article as: Tanislav et al:: Lessons from everyday stroke care for clinical research and vice versa: comparison of a comprehensive and a research population of young stroke patients. BMC Neurology 2014 14:45.

\section{Submit your next manuscript to BioMed Central and take full advantage of:}

- Convenient online submission

- Thorough peer review

- No space constraints or color figure charges

- Immediate publication on acceptance

- Inclusion in PubMed, CAS, Scopus and Google Scholar

- Research which is freely available for redistribution 